\title{
Selective and Protracted Apoptosis in Human Primary Neurons Microinjected with Active Caspase-3, $-6,-7$, and -8
}

\author{
Yan Zhang, ${ }^{1,3}$ Cynthia Goodyer, ${ }^{2}$ and Andréa LeBlanc ${ }^{1,3}$ \\ Departments of ${ }^{1}$ Neurology and Neurosurgery and ${ }^{2}$ Pediatrics, McGill University, Montreal, Quebec, Canada H3A 1W9, \\ and ${ }^{3}$ The Bloomfield Center for Research in Aging, Lady Davis Institute for Medical Research, Jewish General Hospital, \\ Montreal, Quebec, Canada H3T 1E2
}

\begin{abstract}
We have shown previously that caspase-6 is activated in serum deprivation-mediated human neuronal cell death and correlates with increased production of Alzheimer's disease (AD) amyloid $\beta$ peptide $(A \beta)$. Here, we show by direct microinjection of recombinant active enzymes that caspase- 6 (>0.5 pg/cell) induces a protracted course of apoptosis in neurons in a caspase-specific, dose- and time-dependent manner in the presence of serum. Only transient activation of caspase- 6 is required to initiate apoptosis. Caspase- 6 induces apoptosis directly without the activation of other caspase effectors. Doses of caspase- 6 of $<0.25$ $\mathrm{pg} / \mathrm{cell}$ induce only $20 \%$ cell death within $16 \mathrm{~d}$ but render neurons vulnerable to oxidative stress, indicating that caspase activation affects neurons despite the absence of cell death. Caspase-3 induces neuronal apoptosis in $20 \%$ of the cells,
\end{abstract}

whereas caspase-7 or -8 do not induce apoptosis. In contrast, astrocytes undergo apoptosis within $24 \mathrm{hr}$ when microinjected with caspase- 3 but not caspase- $6,-7$, or -8 . These results show cell type-specific vulnerability to caspases in the CNS. The results suggest that activation of caspases in human neurons does not lead to an immediate and rapid process of cell death but provokes a protracted form of apoptosis. Activation of caspases in human neurons may participate in the long-term overproduction of $A \beta$ and other potential toxic fragments resulting from caspase-mediated proteolysis. These results are consistent with the protracted and age-dependent nature of AD.

Key words: caspase; primary neurons; Alzheimer's disease; oxidative stress; astrocytes; apoptosis
Neuronal loss correlates with neuronal dysfunction (Gomez-Isla et al., 1996, 1997) in Alzheimer's disease (AD), and caspases are involved in neuronal death (Masliah et al., 1998; Yang et al., 1998; Gervais et al., 1999; LeBlanc et al., 1999; Selznick et al., 1999; Shimohama et al., 1999; Stadelmann et al., 1999). However, specific features of caspase-mediated neuronal apoptosis are difficult to address in vivo because of the rapid clearance of apoptotic cells from organs. In addition, species and cell type specificity of apoptotic mechanisms make it hard to extrapolate from in vitro to in vivo. We have shown that apoptosis of human primary neurons results in an increased production of amyloid $\beta$ peptide, suggesting that apoptosis-related activation of proteases in implicated in the metabolism of amyloid precursor protein (APP) (LeBlanc 1995). Further studies showed that caspase- $3,-6,-7$, and -8 can cleave APP directly (Barnes et al., 1998; Gervais et al., 1999; LeBlanc et al., 1999; Pellegrini et al., 1999; Weidemann et al., 1999). Furthermore, caspase inhibitors eliminate the apoptosis-mediated increase in amyloid $\beta$ peptide (Barnes et al., 1998; Gervais et al., 1999; LeBlanc et al., 1999). These studies raise the possibility that increased amyloid $\beta$ peptide production is, in some cases, the result of caspase activation. To fully understand the potential impact of caspase activation in human CNS neurodegenerative diseases, it is important to determine how caspase activation affects human CNS neuronal apoptosis.

Caspase-3 and -9 activities are likely critical in developmental neuronal cell death because elimination of caspase- 3 activity leads to extra numbers of neurons in the frontal lobe of animals and premature death of mice (Kuida et al., 1996, 1998; Hakem et al., 1998). Increased immunoreactivity to caspase-3 and to caspase-3-

\footnotetext{
Received June 27, 2000; revised Aug. 16, 2000; accepted Aug. 24, 2000.

This work was supported by the Medical Research Council of Canada and the Fond de Recherche en Santé du Québec to A.L.B. The technical assistance of Beverly Akerman and Jennifer Hammond is gratefully acknowledged.

Correspondence should be addressed to Dr. Andréa LeBlanc, The Bloomfield Center for Research in Aging, Lady Davis Institute for Medical Research, The Sir Mortimer B. Davis Jewish General Hospital, 3755 chemin Côte Sainte-Catherine, Montréal, Québec, Canada H3T 1E2. E-mail: mdal@musica.mcgill.ca.

Copyright (C) 2000 Society for Neuroscience $0270-6474 / 00 / 208384-06 \$ 15.00 / 0$
}

cleaved $\beta$-actin or APP has been shown in AD brains (Masliah et al., 1998; Yang et al., 1998; Gervais et al., 1999; Shimohama et al., 1999). Whereas the immunoreactivity to the CM1 antibody to active caspase- 3 is not increased in neurons associated with senile plaques or neurofibrillary tangles, it is increased in granulovacuolar degeneration in AD (Selznick et al., 1999; Stadelmann et al., 1999). In addition, caspase- 6 and caspase- 9 active p10 fragments increase in AD brain tissue (LeBlanc et al., 1999; Lu et al., 2000). These results implicate caspases in AD pathogenesis. However, the use of postmortem tissue cannot address the initial role of these caspases in human neurons.

To determine which caspase contributes to cell death and altered APP metabolism in human neurons, we have used a unique model of primary cultures of well differentiated human neurons. Caspase-6, but not caspase-3, is activated in serum deprivationmediated human neuronal apoptosis (LeBlanc et al., 1999). Caspase-6 knock-outs are developmentally normal (Zheng et al., 1999), but the role of caspase- 6 in adulthood or aging may be important. Although caspase-1 knock-outs appear normal, they delay Huntington-related symptoms in transgenics carrying excess trinucleotide repeats, indicating that some caspases may function in nonphysiological cell death (Ona et al., 1999). These results warrant further studies on the role of caspase- 6 in human neuronal apoptosis. Here, we directly address the role of caspase-3, -6, -7, and -8 in apoptosis of human neurons and astrocytes by microinjection of recombinant active caspases.

\section{MATERIALS AND METHODS}

Neuron cultures. Primary cultures of neurons were established from cortical and subcortical regions of 12- to 14-week-old fetal brains as described previously, according to ethical regulations of the Medical Research Council of Canada and approved by the McGill University Institutional Review Board (LeBlanc, 1995). Briefly, the brain tissue is dissociated in $0.25 \%$ trypsin, trypsin inactivated with $10 \%$ serum, and the dissociated tissue triturated after addition of $0.1 \mathrm{mg} / \mathrm{ml}$ deoxyribonuclease I. The dissociated tissue is successively passed through 130 and $70 \mu \mathrm{m}$ filters and centrif uged to pellet the cells. The cells are washed once in PBS and once in complete media. The cells are plated at $3 \times 10^{6} / \mathrm{ml}$ on poly-L-lysine-coated tissue culture dishes or ACLAR (33C; $5 \mathrm{~mm}$; Allied Chemical, Minneapolis, $\mathrm{MN}$ ) coverslips in minimal essential media in Earle's balanced salt solution 
containing $0.225 \%$ sodium bicarbonate, $1 \mathrm{~mm}$ sodium pyruvate, $2 \mathrm{~mm}$ L-glutamine, $0.1 \%$ dextrose, $1 \times$ antibiotic Pen-Strep (all products from Life Technologies, Gaithersburg, MD), and 5\% decomplemented fetal bovine serum (HyClone, Logan, UT). One millimolar the anti-mitotic agent 5 'fluoro- 2 -deoxyuridine is added to the culture media after the cells have attached to prevent proliferation of dividing cells. The cells attach rapidly and establish intricate neuritic networks within $3 \mathrm{~d}$. Typically, the culture is composed of $90-95 \%$ neurons and 5-10\% astrocytes that survive in culture for 4-6 weeks (LeBlanc, 1995). Experiments on neurons were conducted at $10 \mathrm{~d}$ of culture.

Microinjection of recombinant caspase-6. Glass micropipettes pulled by a Flaming/Brown micropipette puller (P-87) with a tip diameter of $\sim 0.5 \mu \mathrm{m}$ were used for microinjection. The glass micropipettes were made from 1.0 $\mathrm{mm}$ outer diameter and $0.5 \mathrm{~mm}$ inner diameter thin-walled glass capillaries with microfilaments (borosilicate with filament MTW100F-4; World Precision Instruments, Sarasota, FL). Recombinant active caspase-6 (R Csp-6) (Biomol, Plymouth Meeting, PA) was prepared in caspase-6 active buffer containing $20 \mathrm{~mm}$ piperazine- $N, N^{\prime}$-bis-(2-ethanesulfonic acid) (PIPES), $100 \mathrm{~mm} \mathrm{NaCl}, 10 \mathrm{~mm}$ dithiothreitol (DTT), $1 \mathrm{~mm}$ EDTA, $0.1 \%$ 3-[(3-cholamidopropyl)-dimethylammonio]-2-hydroxy-1-propanesulfonic acid (CHAPS), and 10\% sucrose, pH 7.2. Dextran Texas Red (DTR) (at $100 \mu \mathrm{g} / \mathrm{ml}$ ) (Cedarlane, Hornby, Ontario, Canada) was coinjected with $\mathrm{R}-\mathrm{Csp}-6$ as a fluorescent marker to recognize injected neurons. Control microinjections were made with caspase-6 active buffer and DTR only. As an additional control for the specificity of caspase-6-mediated apoptosis, caspase- 6 was denatured by boiling for $10 \mathrm{~min}$ and injected at $100 \mathrm{pg} / \mathrm{cell}$ Microinjections were performed using an Eppendorf Microinjector 5246 and Micromanipulator (MIS-5000; Burleigh Instruments Inc., Fishers, NY), at an injection pressure of 100 hectoPascal $(\mathrm{hPa})$, compensation pressure of $50 \mathrm{hPa}$, and an injection time of $0.1 \mathrm{sec}$. The injected volume was $1 \mathrm{nl} /$ cell. Neurons were injected into the cytosolic area of the cell soma. Approximately $90 \%$ human neurons survive the microinjection of DTR for at least $16 \mathrm{~d}$ indicating, the resistance of the neurons to the physical stress of microinjection.

For the dose and time response curves, $0.01,0.05,0.1,0.25,0.5,5,10,20$ 50 , or $100 \mathrm{pg} / \mathrm{cell} \mathrm{R}-\mathrm{Csp}-6$ were coinjected with DTR in 100 cells on each of two coverslips per neuron preparation. The injected neurons were incubated for various times at $37^{\circ} \mathrm{C}$ in serum containing normal neuron media in the presence or absence of $5 \mu \mathrm{M}$ BOC-D-fmk, $N$-benzyloxycarbonyl-Val-Ala-Asp-fluoromethyl ketone (Z-VAD-fmk), $N$-benzyloxycarbonyl-Val-Glu-Ile-Asp-fluoromethyl ketone (Z-VEID-fmk), N-benzyloxycarbonyl-Ile-Glu-Thr-Asp-fluoromethyl ketone (Z-IETD-fmk), and $N$-benzyloxycarbonyl-Asp-Glu-Val-Asp-fluoromethyl ketone (Z-DEVDfmk) (Biomol) dissolved at $5 \mathrm{~mm}$ in DMSO. As a control for the solvent, $0.001 \%$ of DMSO was added to DTR-microinjected neurons. The negative controls were injected with DTR prepared in caspase- 6 active buffer. The positive controls were injected with DTR only and treated for $24 \mathrm{hr}$ with $10 \mu \mathrm{M}$ staurosporine to show that neurons can succumb to an apoptotic signal.

Astrocytes were injected at an injection pressure of $50 \mathrm{hPa}$, compensation pressure of $30 \mathrm{hPa}$, and an injection time of $0.1 \mathrm{sec}$. The injected volume was $0.3 \mathrm{nl} /$ cell. Astrocytes were injected into the cytosolic area of the cell soma. Approximately $50 \%$ human astrocytes survive the injection for at least $16 \mathrm{~d}$. Twenty or $100 \mathrm{pg} / \mathrm{cell} \mathrm{R}-\mathrm{Csp}-6$ were coinjected with DTR in 100 cells on each of two coverslips per astrocyte preparation.

Immunostaining of microinjected caspase-6. Microinjected neurons $(0.5$ $\mathrm{pg} /$ cell R-Csp-6) were fixed at $0,1,2,3,4$, and $8 \mathrm{~d}$ after injection in fresh $4 \%$ paraformaldehyde and $4 \%$ sucrose for $20 \mathrm{~min}$ at room temperature and permeabilized in $0.25 \%$ Triton X-100 for $10 \mathrm{~min}$ at room temperature. Ten percent fetal goat serum in PBS was used for blocking for $20 \mathrm{~min}$ at room temperature. Antibody to active caspase-6 p10 fragment (1:250) (PharMingen, San Diego, CA) was incubated for $2 \mathrm{hr}$ at room temperature. Secondary goat anti-mouse antibody conjugated to FITC (1:200) was used for detection.

Sublethal oxidative stress treatment. As an oxidative stress, a subletha dose of $0.1 \mu \mathrm{M} \mathrm{H}_{2} \mathrm{O}_{2}$ was added to the media of R-Csp-6 (0.1 pg/cell) or control microinjected neurons (Paradis et al., 1996). The neurons were incubated for 0,2 , and $4 \mathrm{~d}$ after injection.

Measurement of apoptosis. Neurons and astrocytes were fixed in fresh $4 \%$ paraformaldehyde and $4 \%$ sucrose for $20 \mathrm{~min}$ at room temperature and permeabilized in $0.1 \%$ Triton X-100 and $0.1 \%$ sodium citrate for 2 min on ice. Terminal deoxynucleotidyl transferase-mediated biotinylated UTP nick end labeling (TUNEL) was performed using the in situ cell death detection kit I as described by the manufacturer (Roche Products, Hertforshire, UK). The percentage of neuronal apoptosis was determined by the ratio of the number of DTR and TUNEL double-positive neurons over the total number of DTR-positive neurons. The number of DTR-positive neurons or astrocytes did not decrease with time, indicating the retention of all apoptotic and nonapoptotic microinjected neurons on the coverslip.

Caspase fluorogenic activity assays. Recombinant caspases $-3,-6,-7$, or -8 (PharMingen) were assayed for activity using relevant fluorogenic peptide substrates. Caspase activity in $10 \mathrm{ng}$ of enzyme was measured using $7 \mu \mathrm{M}$ Ac-DEVD-AFC for caspases-3 and -7, Ac-VEID-AFC for caspase-6, and Ac-IETD-AMC (Biomol) in caspase reaction buffer $(20 \mathrm{mM}$ PIPES, $30 \mathrm{~mm}$ $\mathrm{NaCl}, 10 \mathrm{~mm}$ DTT, $1 \mathrm{~mm}$ EDTA, 0.1\% CHAPS, and 10\% sucrose, $\mathrm{pH} 7.2$ ). Release of the fluorogenic moiety Ac, $N$-acetyl coumarin (AFC) or 7-amino-4-trifluoromethyl coumarin (AMC) was monitored over time in a Bio-Rad (Hercules, CA) Fluoromark apparatus. Excitation was at $390 \mathrm{~nm}$ for $\mathrm{AFC}$ or $\mathrm{AMC}$, and emission was at $538 \mathrm{~nm}$ for $\mathrm{AFC}$ or at $460 \mathrm{~nm}$ for
AMC. Readings were recorded at 2 min intervals over $1 \mathrm{hr}$. A standard curve of fluorescence of AFC or AMC allowed calculation of nanomoles of released $\mathrm{AFC} / \mathrm{AMC}$ in the reactions. Specific activities were expressed as nanomoles of AFC/AMC released per microgram of protein per minute, based on the linear range of the curve.

Statistical evaluation of the results. For the dose response, $\mathrm{H}_{2} \mathrm{O}_{2}$ stress, and recombinant caspase-3, -7 , and -8 activities, statistical evaluations were assessed using two-tailed, unpaired Student's $t$ test. For the time and dose response of R-Csp-6, two-way ANOVA was performed with independent variables as time factor $(\mathrm{df}=7)$ and dosage factor $(\mathrm{df}=7)$. Post hoc analysis with two-tailed unpaired $t$ test was applied as a follow-up for the significant difference shown by ANOVA for both time and dosage factors. $p<0.05$ was used as indicative of statistical significance.

\section{RESULTS}

\section{Microinjected recombinant active caspase- 6 confers a dose-dependent increase in apoptosis of primary human neurons in culture}

In our previous study, we showed the loss of procaspase- 6 and the presence of caspase- 6 activity in serum-deprived neurons (LeBlanc et al., 1999). These results indicated that caspase- 6 is responsible for neuronal apoptosis. However, because other proapoptotic proteins may be activated by serum deprivation, we determined whether caspase- 6 activation is directly responsible for neuronal apoptosis by microinjecting serum-treated neurons with various amounts of R-Csp-6 and DTR as a fluorescent marker dye. Apoptosis was identified by TUNEL staining $48 \mathrm{hr}$ after the microinjection. Figure $1 A$ shows a representative example of the detection of DTR-positive (red) and TUNEL-positive (green) in DTRmicroinjected neurons. The TUNEL-positive neuron has the shrunken appearance of apoptotic cells compared with TUNELnegative cells. To determine the life span of the microinjected caspase- 6 in the neurons, we incubated caspase-6-microinjected neurons for 24, 48, 72, and $96 \mathrm{hr}$ and immunostained the cells with a caspase- 6 antibody. The results show the detection of R-Csp-6 in $95 \%$ of microinjected neurons until $24 \mathrm{hr}$ of injection (Fig. $1 B$ ). At $48 \mathrm{hr}$, the immunoreactivity is considerably decreased. At 72 or 96 hr, caspase- 6 is detected only in 2-5\% of injected neurons (results not shown).

Microinjected neurons show a dose-dependent increase in apoptosis from 0.25 to $20 \mathrm{pg} /$ cell R-Csp-6 (Fig. 1C). Higher doses of 50 and $100 \mathrm{pg} / \mathrm{cell}$ do not result in more TUNEL-positive cells. The maximum amount of apoptosis observed at $48 \mathrm{hr}$ is $50 \%$, indicating that some cells are either resistant or undergoing a delayed cell death after microinjection of R-Csp-6. A high dose of kinase inhibitor, staurosporine $(10 \mu \mathrm{M})$, provokes over $90 \%$ cell death within $24 \mathrm{hr}$, indicating that these neurons are able to undergo a rapid apoptotic cell death. Denatured R-Csp-6 (100 pg/cell) was also microinjected to ensure that apoptosis was directly attributable to active caspase- 6 (Fig. 1C). The denatured R-Csp-6 did not cause significant cell death up to $16 \mathrm{~d}$ after injection, suggesting that the dose-dependent apoptosis is specifically induced by R-Csp-6.

To confirm that caspase- 6 is directly responsible for the neuronal apoptosis and is not activating downstream caspases, we tested the effect of general caspase inhibitors BOC-D-fmk and Z-VAD-fmk, caspase-6-specific inhibitor Z-VEID-fmk, caspase-3-specific inhibitor Z-DEVD-fmk, and caspase-8-specific inhibitor Z-IETD-fmk on R-Csp-6-microinjected neurons (Fig. 1D). Z-VEID-fmk was the most potent inhibitor of caspase-6-mediated neuronal apoptosis. The general caspase inhibitors also inhibited caspase-6mediated apoptosis, and Z-DEVD-fmk and Z-IETD-fmk were the least efficient and did not show significant inhibition of caspase-6mediated apoptosis. Because DEVD also inhibits caspase-2, -7, and -10 (Thornberry et al., 1997), these results indicate that active caspase- 6 is lethal to human neurons in the absence of other effector caspase activity.

To determine whether caspase-6-microinjected neurons that do not exhibit neuronal apoptosis $48 \mathrm{hr}$ after microinjection will eventually succumb or are naturally protected against apoptosis, neuronal cell death was examined over time with varying doses of microinjected caspase-6 (Fig. 2A). The results show that even the lowest lethal dose of caspase-6 (0.5 pg/cell) induces cell death in $\sim 90 \%$ of neurons within $6 \mathrm{~d}$ after injection. Thereafter, the remaining $10 \%$ of 
A.

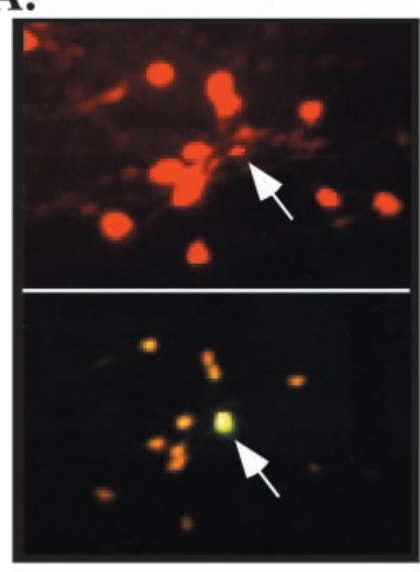

B
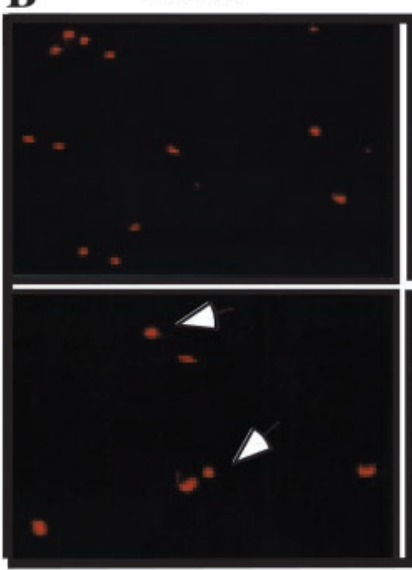

D.
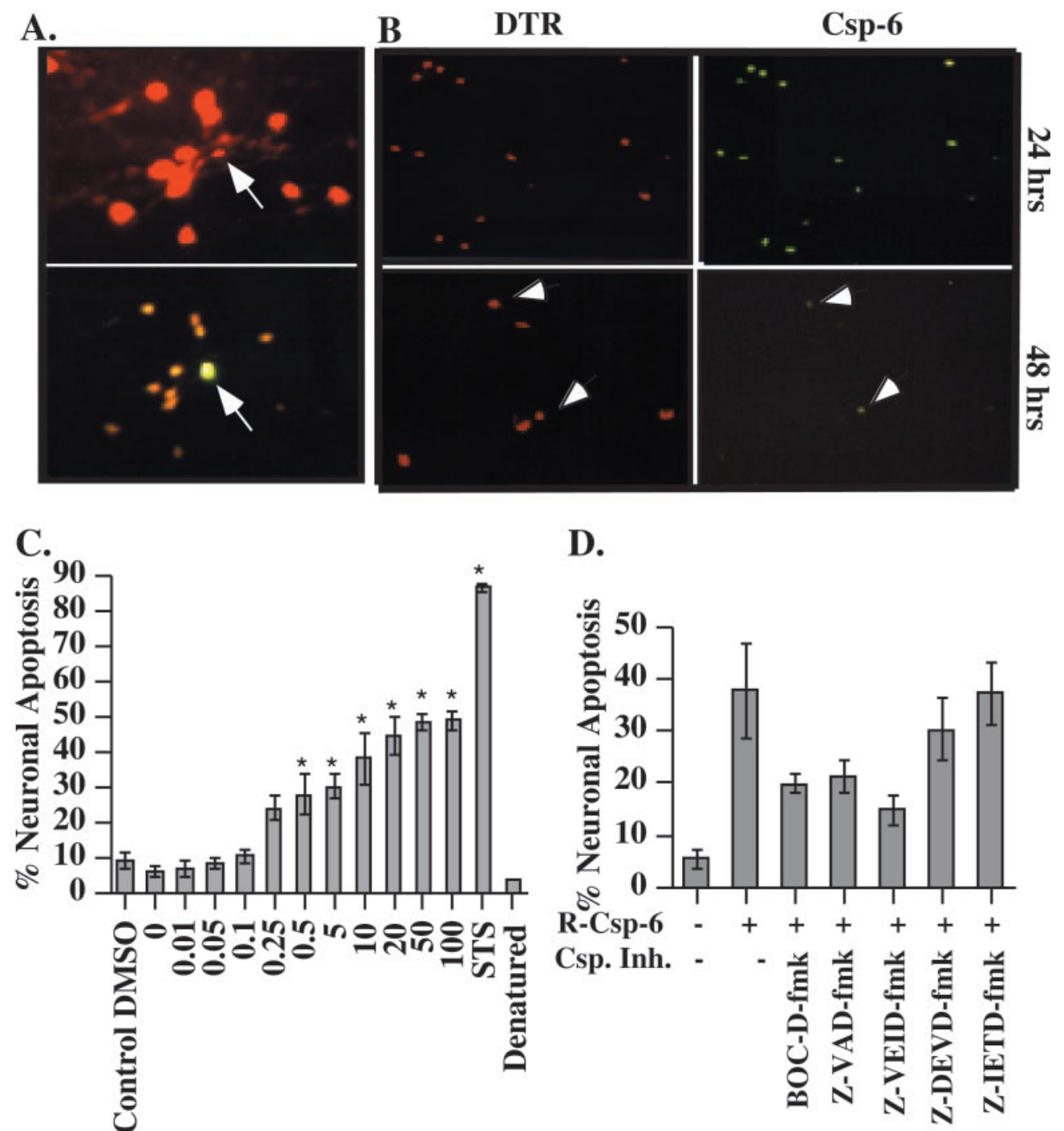

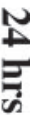

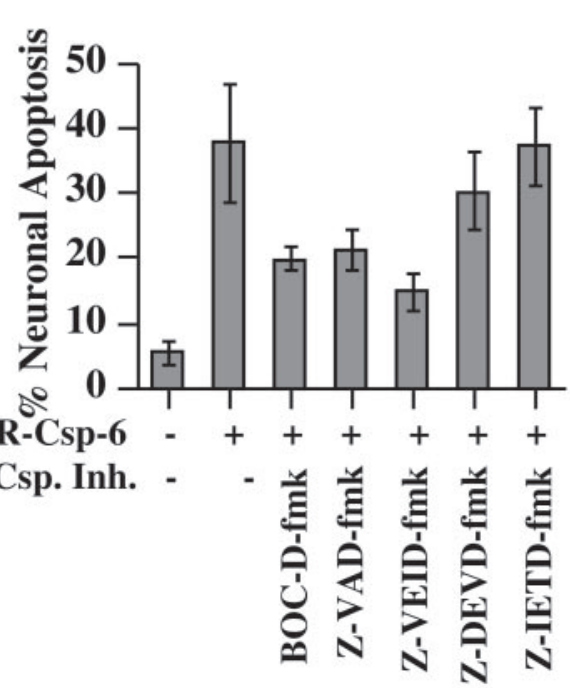

Figure 1. Dose-response curve of R-Csp-6 on neuronal apoptosis. $A$, Detection of apoptotic microinjected neurons. Cells were injected with the marker dye DTR (top), and apoptosis was detected by TUNEL (bottom). The white arrow shows a green TUNEL-positive neuron. $B$, Immunodetection of caspase-6 after microinjection in neurons. Neurons were microinjected with $5 \mathrm{pg} / \mathrm{cell}$ recombinant active caspase-6 and DTR and submitted to immunocytochemistry with monoclonal caspase- 6 p10 antibody at various times after the microinjection. $C$, Survival of neurons microinjected with caspase-6. Neurons in culture were microinjected with DTR and various amounts of R-Csp-6 and stained for TUNEL after 48 hr to determine the percentage of neuronal apoptosis after injection. STS represents apoptosis in non-caspase-6-microinjected neurons incubated with $10 \mu \mathrm{M}$ staurosporine for $24 \mathrm{hr}$. Denatured represents neuronal apoptosis $48 \mathrm{hr}$ after neurons were microinjected with $100 \mathrm{pg} / \mathrm{cell}$ denatured caspase-6. Data represent the mean and SD of four independent experiments. ${ }^{*} p<0.002$. $D$, Caspase- 6 peptide inhibitor effect on cell death. Neurons in culture were microinjected with DTR and $5 \mathrm{pg} / \mathrm{cell} \mathrm{R}-\mathrm{Csp}-6$ and treated in the absence or presence of $5 \mu \mathrm{M}$ caspase inhibitors for $48 \mathrm{hr}$. Data represent the mean and SD. $p<0.004$ for BOC-D-fmk, Z-VAD-fmk, and Z-VEID-fmk.

neurons resist the lethal injection of R-Csp- 6 . The $10 \%$ of remaining neurons are either completely resistant to caspase-6-mediated cell death, or an even longer time is required for apoptosis to occur. A striking feature of these results is the length of time required for neurons to undergo apoptosis after a lethal injection of R-Csp-6. We have also observed this extended death in serum deprivationmediated neuronal loss in which only $35 \%$ of the human neurons show TUNEL-positive apoptosis after $4 \mathrm{~d}$ of serum deprivation (Fig. $3 B$ ). In contrast, staurosporine-mediated cell death occurs within $24 \mathrm{hr}$ (Fig. 1C). These results indicate that caspase-6 induces a protracted course of apoptosis in human neurons.

A dose of $0.05-0.25 \mathrm{pg} /$ cell R-Csp-6 leads to only $18-24 \%$ apoptosis within $16 \mathrm{~d}$, whereas no cell death is detected with 0.01 pg/cell R-Csp-6 (Fig. 2A). This finding raises the possibility that, although these low doses of R-Csp- 6 cannot induce significant cell death, they may act on neuronal protein substrates and alter cellular homeostasis. To determine whether the neurons microinjected with sublethal doses of caspase- 6 are more vulnerable to a secondary insult, we treated neurons with serum deprivation or a sublethal dose of oxidative stress $\left(0.1 \mu \mathrm{M} \mathrm{H}_{2} \mathrm{O}_{2}\right)$ after microinjec- tion with $0.1 \mathrm{pg} / \mathrm{cell} \mathrm{R}-\mathrm{Csp}-6$ (Fig. 3). The results show that microinjection of $0.1 \mathrm{pg} /$ cell R-Csp-6 does not cause cell death after 48 or $96 \mathrm{hr}$. The induction of apoptosis by serum deprivation in non-R-Csp-6-microinjected cells is slightly, but not significantly, exacerbated by R-Csp-6 at 48 or $96 \mathrm{hr}(p<0.2)$. In contrast, a 0.1 $\mu \mathrm{M}$ dose of $\mathrm{H}_{2} \mathrm{O}_{2}$, which in the absence of R-Csp- 6 does not induce apoptosis, significantly enhances neuronal apoptosis by $96 \mathrm{hr}$ of treatment ( $p \leq 0.004)$. These results indicate that lower doses of active R-Csp-6 are detrimental to neurons and render neurons vulnerable to oxidative stress but not to growth factor deprivation. Therefore, low levels of caspase- 6 activation could account for increased neuronal vulnerability in aging and neurodegenerative diseases in which oxidative stress is strongly suspected.

\section{Human neurons are more susceptible to caspase- 6 than to caspases-3, -7 , or -8}

Many investigators have reported that activation of caspase-3 is important in neuronal apoptosis (Du et al., 1997; Keane et al., 1997; Yakovlev et al., 1997; Barnes et al., 1998; Srinivasan et al., 1998). Particularly, the study of caspase-3 and -9 knock-out mice, 

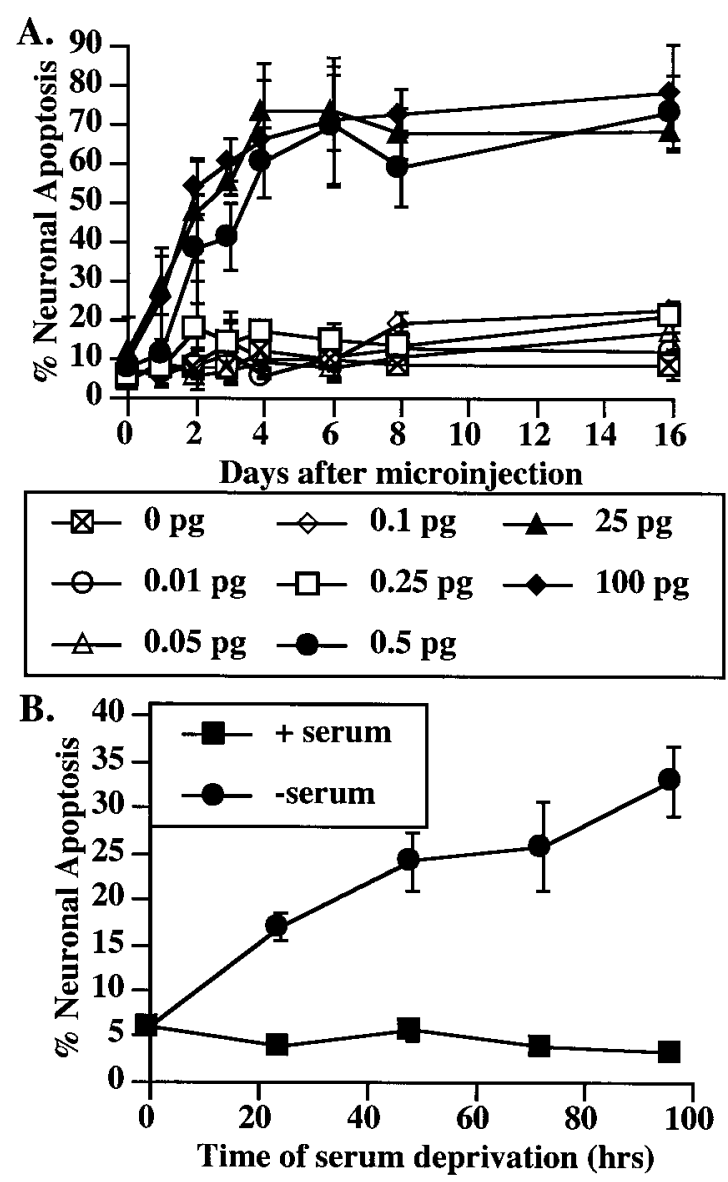

Figure 2. Time-dependent cell death by microinjected R-Csp-6. A, Microinjected neurons were assayed for apoptosis from 1 to $16 \mathrm{~d}$. Data represent the mean and SD from three independent neuron preparations. Two-way ANOVA on doses $\geq 0.25 \mathrm{pg} /$ cell and time factors ( $\mathrm{df}=7$ for both) results in a statistical significance of $p<0.001$. Doses of 0.1 and $0.05 \mathrm{pg} / \mathrm{cell}$ showed a statistically significant increase of apoptosis at 6 and $16 \mathrm{~d}$, respectively. In time, doses of $0.5 \mathrm{pg} / \mathrm{cell}$ and above were significantly different at $1 \mathrm{~d}$ after microinjection, whereas $0.25 \mathrm{pg} /$ cell required $2 \mathrm{~d}$. No increase in apoptosis was observed in time with 0.01 and $0.05 \mathrm{pg} / \mathrm{cell}$ up to $16 \mathrm{~d}$ after microinjection. $B$, Percentage of apoptotic neurons in serumdeprived neurons. Data represent the mean and SEM from 18 independent neuron preparations.

showing abrogation of the developmentally regulated neuronal cell death in the forebrain, provides convincing evidence for an important role of caspase-3 and -9 in neuronal apoptosis (Kuida et al., 1996, 1998; Hakem et al., 1998; Zheng et al., 1999). Because caspase-6 can activate caspase-3 (Orth et al., 1996) and to determine whether caspase- 3 or other caspases can also cause apoptosis of human neurons in a manner similar to R-Csp-6, we microinjected 20 and $100 \mathrm{pg} /$ cell recombinant caspases-3, -7, and -8 in neurons (Fig. $4 A$ ). These recombinant caspases show strong specific activity, as determined by in vitro fluorogenic assay (Fig. 4B). However, we find that only caspase- 6 induces significant cell death in the human neurons, even $16 \mathrm{~d}$ after microinjection of $100 \mathrm{pg} / \mathrm{cell}$. Caspase- 3 induces a slight increase in apoptosis at the dosages of 20 and $100 \mathrm{pg} / \mathrm{cell}(p<0.05)$. These results indicate that differentiated human primary neurons are more resistant to caspases-3, -7 , and -8 than to caspase- 6 .

\section{Human astrocytes are more susceptible to caspase-3 than to caspase- 6,7 , or 8}

To determine whether other CNS cell types are vulnerable to caspase- 6 or other caspases, human astrocytes were microinjected with 20 and $100 \mathrm{pg} / \mathrm{cell}$ recombinant caspase-3, -6, -7, and -8 (Fig. 5). In contrast to neurons, astrocytes undergo apoptosis with caspase- 3 but not caspase- $6,-7$, or -8 . These results show CNS cell

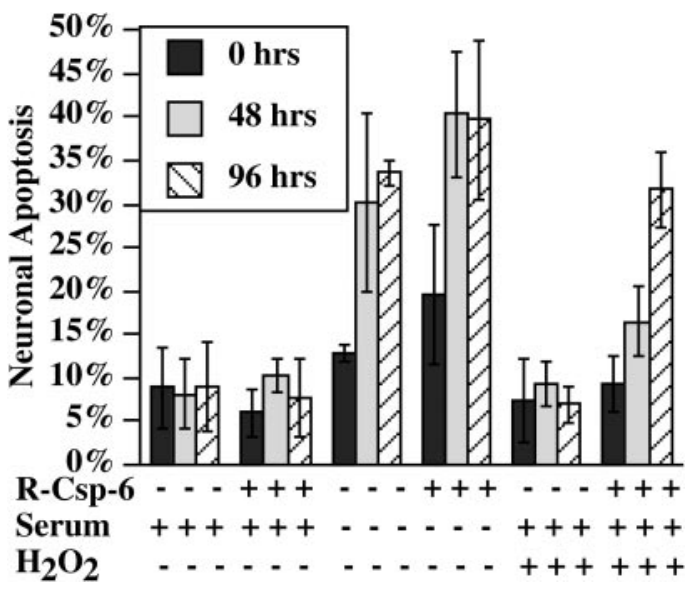

Figure 3. Sublethal dose of caspase-6 renders neurons vulnerable to normally nonlethal doses of oxidative stress. Neurons were microinjected with DTR in the absence or presence of $0.1 \mathrm{pg} / \mathrm{cell} \mathrm{R}-\mathrm{Csp}-6$ and submitted to serum deprivation or $0.1 \mu \mathrm{M} \mathrm{H}_{2} \mathrm{O}_{2}$. Cells were fixed at 0,48 , and $96 \mathrm{hr}$ and analyzed for apoptosis by TUNEL. Data represent the mean and SD of three independent neuron preparations.

type vulnerability to different caspases. In addition, the astrocytes undergo maximal apoptosis within $24 \mathrm{hr}$ after microinjection. These results confirm that the caspase-mediated apoptosis in neurons is protracted compared with other cell types.

\section{DISCUSSION}

Resolving the role of caspase activation in neuronal apoptosis is fundamental to the understanding of neurodegenerative diseases. Generally, caspases are considered effectors of programmed cell death. The role of caspases in AD is supported by evidence of increased caspase-3, caspase-6, and caspase-9 immunoreactivity or activation in AD brain tissue (Masliah et al., 1998; Yang et al., 1998; Gervais et al., 1999; LeBlanc et al., 1999; Selznick et al., 1999; Shimohama et al., 1999; Stadelmann et al., 1999; Lu et al., 2000), the observation that Alzheimer's-associated proteins, presenilins, and APP are substrates of caspases (Kim et al., 1997; Loetscher et al., 1997; Barnes et al., 1998; Gervais et al., 1999; LeBlanc et al., 1999; Pellegrini et al., 1999; Weidemann et al., 1999), and the fact that amyloid $\beta$ peptide, AD-linked mutations, or overexpression of APP and presenilins induce neuronal apoptosis (Yankner et al., 1989; Loo et al., 1993; Wolozin et al., 1996; Kim et al., 1997; Nishimura et al., 1998). However, the protracted course of AD and the difficulty in detecting considerable numbers of apoptotic neurons in postmortem tissue argues against apoptosis being responsible for neuronal dysfunction and cell loss in AD (Stadelmann et al., 1998).

In the present manuscript, we evaluated the role of caspase activation in neuronal apoptosis of human primary neurons. We have shown previously the activation of caspase- 6 , but not caspase-3, in serum deprivation-mediated apoptosis of these highly differentiated primary cultures of human neurons (LeBlanc et al., 1999). However, a number of other proapoptotic proteins may be activated by serum deprivation, raising the possibility that neuronal apoptosis is not mediated directly by caspase-6. Our study shows six striking features of caspase-mediated neuronal apoptosis.

First, caspase-6 is directly responsible for neuronal apoptosis. We find that neurons microinjected with caspase-6 undergo apoptosis in the presence of complete media. The possibility that caspase- 6 is activating other effector caspases was eliminated by showing that neither caspase- 3 nor caspase- 8 caspase peptide inhibitors prevent caspase-6-mediated cell death. As expected, the caspase-6-specific inhibitor Z-VEID-fmk and general caspase inhibitors significantly prevent apoptosis of caspase-6-microinjected neurons. These results eliminate the possibility that proteins other than caspase- 6 are responsible for neuronal apoptosis and reasonably demonstrate that caspase- 6 acts as an effector caspase in these 

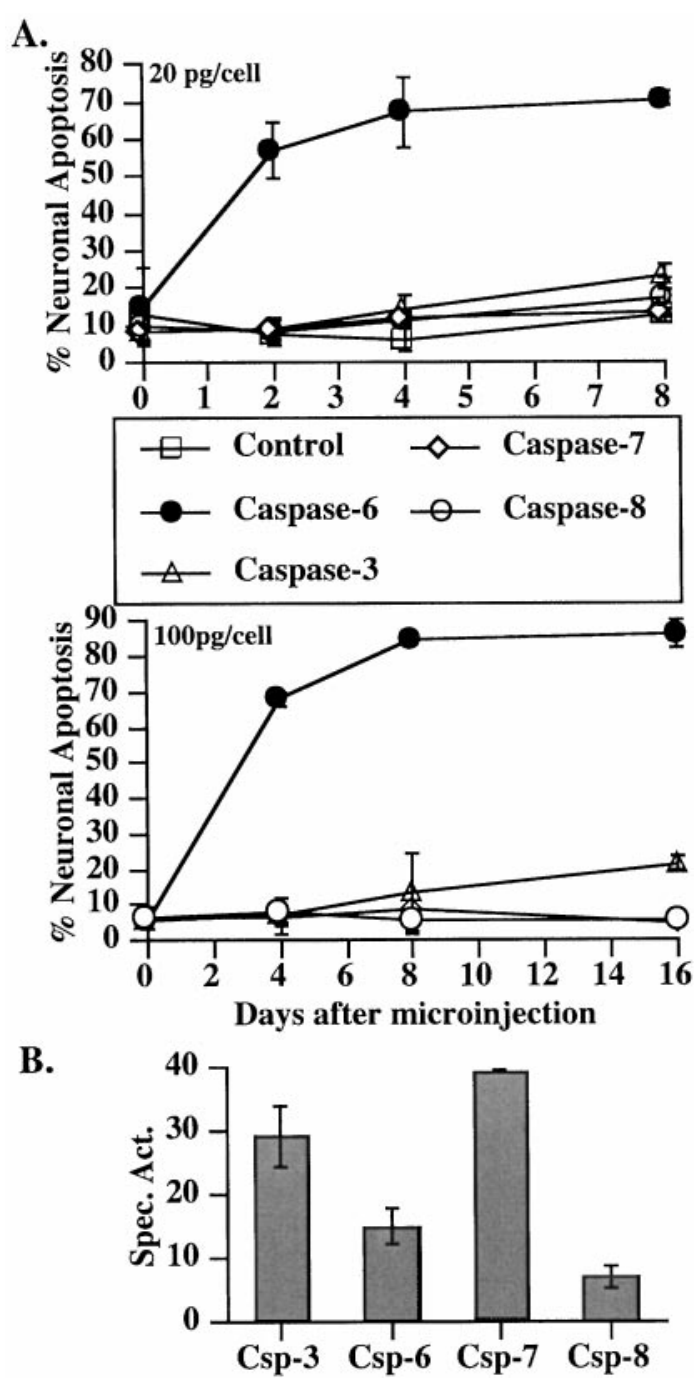

Figure 4. Human neurons are resistant to caspase-3, -7, and -8. A, Neurons were injected with 20 or $100 \mathrm{pg} / \mathrm{cell}$ recombinant caspases. Cells were fixed at the indicated times and stained for TUNEL. Data represent the mean and SD of three neuronal preparations. There is no statistical difference between the DTR-injected and caspases-3-, -7-, or -8-injected neurons, except in caspase-3 at $4(p=0.01)$ and $8(p=0.04) \mathrm{d}$. $B$, The activity of each recombinant caspases was verified by fluorogenic substrate assay. Data represent the mean and SD of three independent experiments

neurons. The known substrates of caspase-6 are lamin A and amyloid precursor protein (Gervais et al., 1999; LeBlanc et al., 1999; Nicholson, 1999; Pellegrini et al., 1999). Whether the downstream events of caspase-6-mediated cell death requires proteolysis of these proteins remains to be determined. Caspase cleavage of the APP C-terminal 31 amino acids can increase the vulnerability of cells to a cytotoxic insult ( $\mathrm{Lu}$ et al., 2000). It is reasonable to assume that caspase- 6 initiates downstream events that eventually result in the demise of the cell.

Second, a threshold level of caspase- 6 is required to induce apoptosis. Lower levels of active caspase- 6 do not induce neuronal apoptosis but render neurons vulnerable to a secondary insult. The $0.5 \mathrm{pg}$ of R-Csp-6 required to induce maximal apoptosis is $\sim 70$ times the amount observed in serum-deprived apoptotic neurons at $12 \mathrm{hr}$ of serum deprivation (LeBlanc et al., 1999). This level is comparable with the expression levels obtained in transfected cell lines. The lack of apoptosis in neurons microinjected with caspase- 6 at $0.25 \mathrm{pg} / \mathrm{cell}$ or less is intriguing. These neurons are not normal, as shown by the addition of a sublethal dose of oxidative stress. $\mathrm{H}_{2} \mathrm{O}_{2}$ at $0.1 \mu \mathrm{M}$ increases apoptosis in neurons microinjected with $0.1 \mathrm{pg} / \mathrm{cell} \mathrm{R}-\mathrm{Csp}-6$. Therefore, it appears that caspase activation does not necessarily induce apoptosis but renders neurons

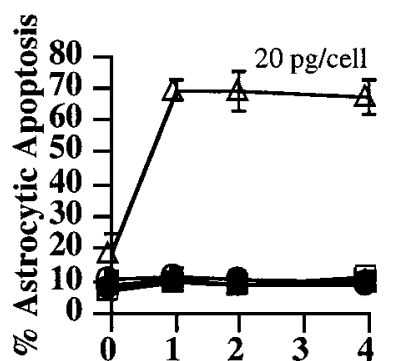

Days after microinjection

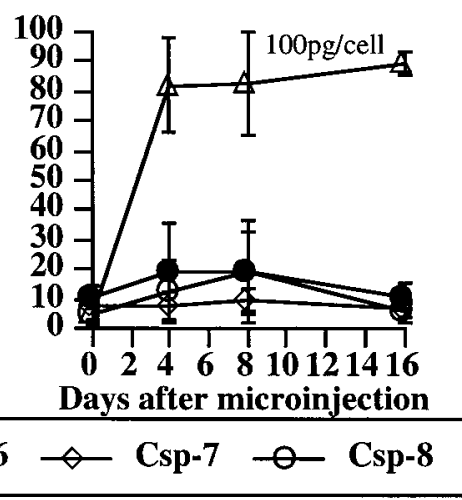

Figure 5. Astrocytes are resistant to caspase-6, -7 , and -8 but undergo apoptosis with caspase-3. Astrocytes were injected with 20 or $100 \mathrm{pg} / \mathrm{cell}$. Apoptosis was determined by TUNEL. Data represents the mean and SD of two experiments from three astrocyte preparations. Statistical difference is achieved only with caspase-3 $(p<0.0001)$.

vulnerable to oxidative stress, a well known age-dependent stress of the brain. Together, these results demonstrate that the level of active caspase in neurons can result in either immediate or delayed apoptosis.

Third, we show that the microinjected caspase- 6 disappears from most injected cells within $48 \mathrm{hr}$. Yet, $80-90 \%$ of these microinjected neurons become apoptotic within $6 \mathrm{~d}$ of microinjection. These results indicate that caspase-6-mediated apoptosis requires only transient activation. Therefore, the detection of caspases may be impossible to detect at the end point of neurodegeneration in postmortem tissue, and the absence of detectable active caspase fragments may not necessarily indicate normal neurons. These results may explain the discrepancy between the detection of caspase-cleaved proteins such as $\beta$-actin and amyloid precursor protein and active caspases in AD postmortem tissues (Yang et al., 1998; Gervais et al., 1999; Selznick et al., 1999; Stadelmann et al., 1999).

Fourth, our study demonstrates that $10 \%$ of neurons microinjected with a lethal dose of R-Csp- 6 resist apoptosis up to $16 \mathrm{~d}$ after the microinjection. These results show that neurons can resist certain levels of active caspase- 6 without an absolute commitment to cell death. These neurons may represent a subspecies of neurons that are either insensitive to active caspase- 6 or contain high levels of natural inhibitors of caspase- 6 . The resistance of some of the human primary neurons to caspase- 6 could explain the selective neuronal cell death that occurs in neurodegenerative diseases.

Fifth, the microinjected neurons undergo an extended form of apoptosis, even with the highest lethal dose of caspase-6. This elongated mode of cell death is also observed in serum-deprived neurons in which only $35 \%$ of apoptosis occurs after $4 \mathrm{~d}$. Although it could be argued that terminally differentiated neurons have become resistant to growth factor deprivation, the direct microinjection of active caspase- 6 in neurons indicates an unusual extended form of cell death. In contrast, staurosporine treatment of neurons or microinjection of recombinant caspase- 3 in astrocytes induces rapid apoptosis within $24 \mathrm{hr}$. These results suggest that human neurons submitted to caspase- 6 activation do not undergo the rapid type of apoptosis observed in many cell lines. In humans, neurons have to survive for 8-10 decades, and these cells probably have evolved the best survival mechanisms to prevent rapid loss of this essential cell type. We propose that the extended death of the human neuron is the result of the presence of endogenous caspase inhibitors or activation of a number of survival programs responsible for counteracting various insults. This feature is likely one of all long-lived cell types.

Last, the resistance of the human neurons to microinjected recombinant active caspase $-3,-7$, and -8 is also very surprising. In contrast to caspase-6, caspase- 3 induces only a slight, albeit statistically significant, increase in neuronal apoptosis, whereas 
caspases-7 and -8 do not increase apoptosis. We had presumed that active caspase- 3 would result in significant neuronal cell death. Others have shown the importance of caspase-3 in developmental neuronal cell death of mice (Kuida et al., 1996; Srinivasan et al., 1998), and there is evidence for the role of caspase-3 activation in AD (Kim et al., 1997; Masliah et al., 1998; Yang et al., 1998; Gervais et al., 1999; Selznick et al., 1999; Stadelmann et al., 1999). The resistance of neurons to caspase-3 may indicate the presence of strong natural inhibitors of caspase- 3 such as the inhibitors of apoptosis (IAPs) (Roy et al., 1997) or the lack of downstream pathways leading to apoptosis. Whether IAPs decrease with age or with various insults remains to be determined but our results suggest the presence of strong inhibitors of caspase- 3 in healthy neurons but not in astrocytes. Conversely, endogenous caspase- 6 inhibitors may be present in astrocytes but not in neurons. The IAPs do not inhibit caspase-6; therefore, other inhibitors must be present in these cells.

Together, these findings are consistent with the protracted course and the age-dependent characteristics of AD. Therefore, activation of caspases in vivo may not be directly linked to immediate neuronal apoptosis in the CNS. However, the neurons are not necessarily normal. Apoptosis of human neurons increase the production of amyloid $\beta$ peptide, and caspases are involved in APP and presenilin proteolytic processing (LeBlanc, 1995; Kim et al., 1997; Loetscher et al., 1997; Barnes et al., 1998; Gervais et al., 1999; LeBlanc et al., 1999; Pellegrini et al., 1999; Weidemann et al., 1999). Therefore, this extended type of apoptosis in human neurons could result over time in a significant increased production of amyloid $\beta$ peptide, as well as in the degradation of other functional neuronal proteins such as presenilins, leading to a dysfunctional neuron long before neuronal cell death. In addition, similar to neurons in culture, AD neurons with increased levels of active caspases could be induced to undergo apoptosis by a secondary insult such as oxidative stress, which is a well known age-dependent stress of the brain and is believed to play an important role in neurodegenerative diseases (Mattson et al., 1999).

\section{REFERENCES}

Barnes N, Li L, Yoshikawa K, Schwartz L, Oppenheim R, Milligan C (1998) Increased production of amyloid precursor protein provides a substrate for caspase-3 in dying motorneurons. J Neurosci 18:5869-5880.

Du Y, Dodel R, Bales K, Jemmerson R, Hamilton-Byrd E, Paul S (1997) Involvement of a caspase-3-like cysteine protease in 1-methyl-4phenylpyridinium-mediated apoptosis of cultured cerebellar granule neurons. J Neurochem 69:1382-1388.

Gervais F, Xu D, Robertson G, Vaillancourt J, Zhu Y, Huang J, LeBlanc A, Smith D, Rigby M, Shearman M, Clarke E, Zheng H, Van Der Ploeg L, Ruffolo S, Thornberry N, Xanthoudakis S, Zamboni R, Roy S, Nicholson D (1999) Involvement of caspases in proteolytic cleavage of Alzheimer's $\beta$-amyloid precursor protein and amyloidogenic $\beta$-peptide formation. Cell 97:395-406.

Gomez-Isla T, Hollister R, West H, Mui S, Growdon J, Petersen R, Parisi J, Hyman B (1996) Neuronal loss correlated with but exceeds neurofibrillary tangles in Alzheimer's disease. Ann Neurol 41:17-24.

Gomez-Isla T, Price J, McKeel D, Morris J, Growdon J, Hyman B (1997) Profound loss of layer II entorhinal cortex neurons occurs in very mild Alzheimer's disease. J Neurosci 16:4491-4500.

Hakem R, Hakem A, Duncan GS, Henderson JT, Woo M, Soengas MS, Elia A, de la Pompa JL, Kagi D, Khoo W, Potter J, Yoshida R, Kaufman SA, Lowe SW, Penninger JM, Mak TW (1998) Differential requirement for caspase 9 in apoptotic pathways in vivo. Cell 94:339-352.

Keane R, Srinivasan A, Foster L, Testa M, Ord T, Nonner D, Wang H, Reed J, Bredesen D, Kayalar C (1997) Activation of CPP32 during apoptosis of neurons and astrocytes. J Neurosci Res 48:168-180.

Kim T, Pettingell W, Jung Y, Kovacs D, Tanzi R (1997) Alternate cleavage of Alzheimer-associated presenilins during apoptosis by a caspase-3 family protease. Science 277:373-376.

Kuida K, Zheng TS, Na S, Kuan C-Y, Yang D, Karasuyama H, Rakic P, Flavell RA (1996) Decreased apoptosis in the brain and premature lethality in CPP32-deficient mice. Nature 384:368-372.

Kuida K, Haydar TF, Kuan CY, Gu YTC, Karasuyama H, Su MS, Rakic P, Flavell RA (1998) Reduced apoptosis and cytochrome c-mediated caspase activation in mice lacking caspase 9. Cell 94:325-337.

LeBlanc AC (1995) Increased production of $4 \mathrm{kDa}$ amyloid $\beta$ peptide in serum deprived human primary neuron cultures: possible involvement of apoptosis. J Neurosci 15:7837-7846.
LeBlanc AC, Liu H, Goodyer C, Bergeron C, Hammond J (1999) Caspase- 6 role in apoptosis of human neurons, amyloidogenesis and Alzheimer's Disease. J Biol Chem 274:23426-23436.

Loetscher H, Deuschle U, Brockhaus M, Reinhardt D, Nelboeck P, Mous J, Grunberg J, Haass C, Jacobsen H (1997) Presenilins are processed by caspase-type proteases. J Biol Chem 272:20655-20659.

Loo D, Copani A, Pike CJ, Whittemore E, Walencewicz AJ, Cotman CW (1993) Apoptosis is induced by $\beta$-amyloid in cultured central nervous system neurons. Proc Natl Acad Sci USA 90:7951-7955.

Lu DC, Rabizadeh S, Chandra S, Shayya RF, Ellerby LM, Ye X, Salvesen GS, Koo EH, Bredesen DE (2000) A second cytotoxic proteolytic peptide derived from amyloid beta-protein precursor. Nat Med 6:397-404.

Masliah E, Masliah M, Alford M (1998) Caspase dependent DNA fragmentation might be associated with excitotoxicity in Alzheimer's disease. J Neuropath Exp Neurol 57:1041-1052.

Mattson M, Pedersen W, Duan W, Culmsee C, Camandola S (1999) Cellular and molecular mechanisms underlying perturbed energy metabolism and neuronal degeneration in Alzheimer's and Parkinson's diseases. Ann NY Acad Sci 893:154-175.

Nicholson D (1999) Caspase structure, proteolytic substrates, and function during apoptotic cell death. Cell Death Differ 6:1028-1042.

Nishimura I, Uetsuki T, Dani SU, Oshawa Y, Saito I, Okamura H, Uchiyama Y, Yoshikawa K (1998) Degeneration in vivo of rat hippocampal neurons by wild-type Alzheimer amyloid precursor protein overexpressed by adenovirus-mediated gene transfer. J Neurosci 18:2387-2398.

Ona VO, Li M, Vonsattel JP, Andrews LJ, Khan SQ, Chung W M, Frey AS, Menon AS, Li XJ, Stieg PE, Yuan J, Penney JB, Young AB, Cha JH, Friedlander RM (1999) Inhibition of caspase-1 slows disease progression in a mouse model of Huntington's disease. Nature 399:263-267.

Orth K, O'Rourke K, Salvesen G, Dixit V (1996) Molecular ordering of apoptotic mammalian CED-3/ICE-like proteases. J Biol Chem 271:20977-20980.

Paradis E, Douillard H, Koutroumanis M, Goodyer C, LeBlanc A (1996) Amyloid $\beta$ peptide of Alzheimer's disease downregulates Bcl-2 and upregulates Bax expression in human neurons. J Neurosci 16:7533-7539.

Pellegrini L, Passer B, Tabaton M, Ganjei K, D'Adamio L (1999) Alternative, non-secretase processing of Alzheimer's $\beta$-amyloid precursor protein during apoptosis by caspase-6 and -8 . J Biol Chem 274:21011-21016.

Roy N, Deveraux QL, Takahashi R, Salvesen GS, Reed JC (1997) The c-IAP-1 and c-IAP-2 proteins are direct inhibitors of specific caspases. EMBO J 16:6914-6925.

Selznick L, Holtzman D, Han B, Gokden M, Srinivasan A, Johnson E, Roth K (1999) In situ immunodetection of neuronal caspase-3 activation in Alzheimer's disease. J Neuropathol Exp Neurol 58:1020-1026.

Shimohama S, Tanino H, Fujimoto S (1999) Changes in caspase expression in Alzheimer's disease: comparison with development and aging. Biochem Biophys Res Commun 256:381-384.

Srinivasan A, Roth KA, Sayers RO, Shindler KS, Wong AM, Fritz LC, Tomaselli KJ (1998) In situ immunodetection of activated caspase-3 in apoptotic neurons in the developing nervous system. Cell Death Differ 5:1004-1016.

Stadelmann C, Bruck W, Bancher C, Jellinger K, Lassmann H (1998) Alzheimer Disease: DNA fragmentation indicates increased neuronal vulnerability, but no apoptosis. J Neuropathol Exp Neurol 57:456-464.

Stadelmann C, Deckwerth T, Srinivasan A, Bancher C, Bruck W, Jellinger K, Lassmann H (1999) Activation of caspase-3 in single neurons and autophagic granules of granulovacuolar degeneration in Alzheimer's disease. Am J Pathol 155:1459-1466.

Thornberry NA, Rano T, Peterson E, Rasper D, Timkey T, Garcia-Calvo M, Houtzager V, Nordstrom P, Roy S, Vaillancourt JP, Chapman K, Nicholson DW (1997) A combinatorial approach defines specificities of members of the caspase family and granzyme B. J Biol Chem 272:17907-17911.

Weidemann A, Paliga K, Durrwang U, Reinhard F, Zchuckert O, Evin G, Masters CL (1999) Proteolytic processing of the Alzheimer's Disease amyloid precursor protein within its cytoplasmic domain by caspase-like enzymes. J Biol Chem 274:5823-5829.

Wolozin B, Iwasaki K, Vito P, Ganjei JK, Lacana E, Sunderland T, Zhao B, Kusiak JW, Wasco W, D'Adamio L (1996) Participation of presenilin 2 in apoptosis: enhanced basal activity conferred by an Alzheimer mutation. Science 274:1710-1713.

Yakovlev A, Knoblach S, Fan L, Fox G, Goodnight R, Faden A (1997) Activation of CPP32-like caspases contributes to neuronal apoptosis and neurological dysfunction after traumatic brain injury. J Neurosci 17:7415-7424.

Yang F, Sun X, Beech W, Teter B, Wu S, Sigel J, Frautschy S, Cole G (1998) Antibody to caspase-cleaved actin detects apoptosis in differentiated neuroblastoma and neurons and plaque microglia in Alzheimer's disease. Am J Pathol 152:379-389.

Yankner BA, Dawes LR, Fisher S, Villa-Komaroff L, Oster-Granite M, Neve RL (1989) Neurotoxicity of a fragment of the amyloid precursor protein associated with Alzheimer's disease. Science 245:417-420.

Zheng T, Hunot S, Kuida K, Flavell R (1999) Caspase knockouts: matters of life and death. Cell Death Differ 6:1043-1053. 